\title{
Cambio global: una mirada desde la biología
}

\section{Global change: a biological perspective}

Iniciaré este comentario editorial haciendo presente que entre el 2 y el 13 de diciembre Chile albergará en Santiago por primera vez la conferencia sobre el Cambio Climático COP25, esperándose la participación de 30 jefes de Estado y un total de 25.000 participantes en esta mega-conferencia mundial. Lo cual demuestra la importancia que tiene este crucial problema mundial.

Cambio global es el conjunto de cambios ambientales que se derivan de las actividades humanas sobre el planeta, con especial referencia a cambios en los procesos que determinan el funcionamiento del sistema Tierra.

En el siguiente diagrama se exponen los principales aspectos que aportan al Cambio Global.

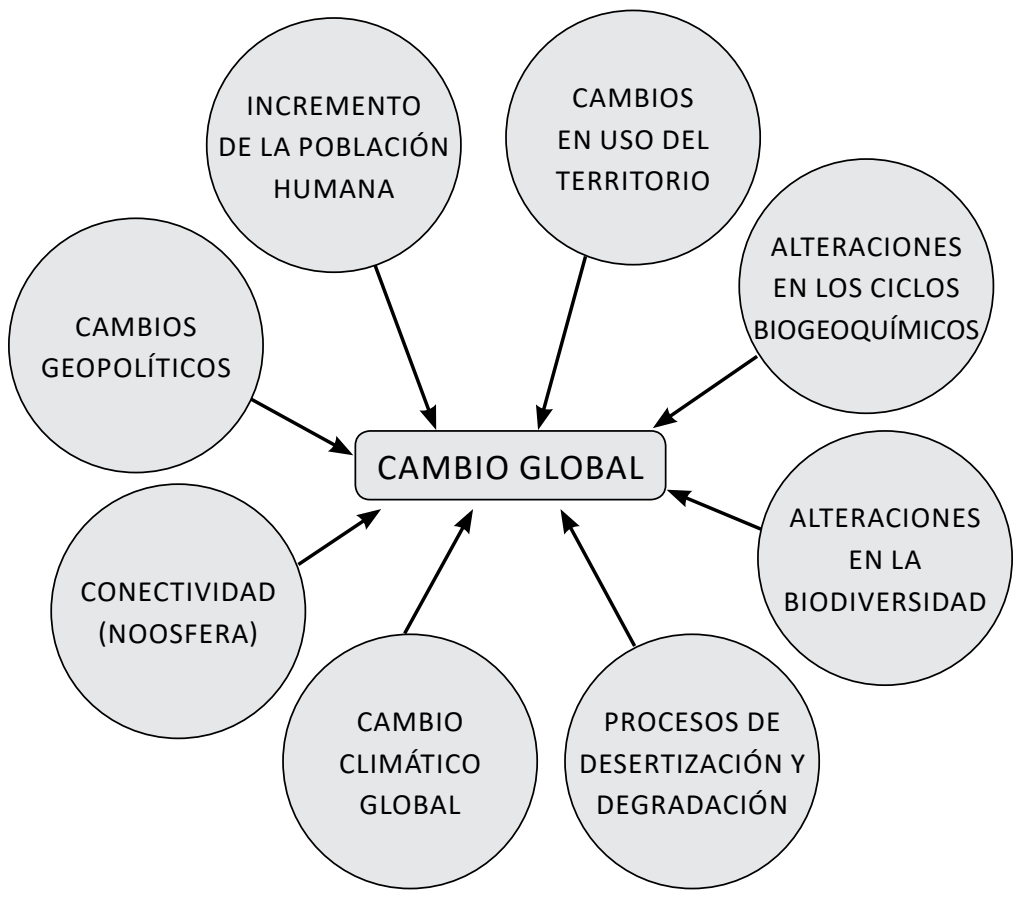

La Tierra recibe en forma permanente la radiación solar, parte de la cual es reflejada al espacio por las nubes. Sin embargo, la mayor parte de dicha radiación atraviesa la atmósfera y alcanza la superficie terrestre. Esta energía proveniente del Sol se denomina radiación solar o de longitud de onda corta que calienta la superficie de la Tierra y los océanos. Como resultado de ello, la Tierra se calienta y emite energía de regreso a la atmósfera de longitud de onda larga (infrarroja) que debiera regresar al espacio exterior. Pero, parte de esta radiación es atrapada por los "gases de efecto invernadero" que calientan la atmósfera.

\section{Efecto invernadero}

En la atmósfera existen gases de 'efecto invernadero', que atrapan el calor emitido por la Tierra y lo mantienen dentro de la atmósfera, actuando a modo de un "gigantesco invernadero". A este fenómeno se le conoce como 'efecto invernadero'. 
El efecto invernadero es un fenómeno natural que se presenta en cualquier planeta o satélite natural que tenga atmósfera y que posea una importante fuerza de gravedad que la mantenga sin perder su cubierta gaseosa. Si la Tierra no tuviera atmósfera sería $33^{\circ} \mathrm{C}$ más fría que la temperatura promedio actual; o sea tendría una temperatura promedio de $-18^{\circ} \mathrm{C}$ y estaría permanentemente cubierta de hielo. Por lo tanto, el efecto invernadero es un fenómeno indispensable para desarrollar y mantener la vida en la Tierra.

\section{¿Qué gases son considerados invernaderos?}

La Tierra tiene $15^{\circ} \mathrm{C}$ temperatura promedio y debe emitir la misma cantidad de energía que recibe con el fin de mantener su equilibrio radiativo y no superar este promedio de $15^{\circ} \mathrm{C}$. Si esto no se logra, la Tierra se va calentado progresivamente.

La composición de la atmósfera ha variado, especialmente por acción antropogénica. Son gases invernaderos todas las moléculas con 3 o más átomos, como por ejemplo el agua $\left(\mathrm{H}_{2} \mathrm{O}\right)$, el dióxido de carbono $\left(\mathrm{CO}_{2}\right)$, el óxido nitroso $\left(\mathrm{N}_{2} \mathrm{O}\right)$, el hexafluoruro de azufre $\left(\mathrm{SF}_{4}\right)$ productos de la combustión de productos fósiles, debido a que ellas absorben la radiación infrarroja emitida por la Tierra produciéndose en estas moléculas vibración o rotación de sus átomos, por ende, se calientan. El ozono $\mathrm{O}_{3}$ también es un gas invernadero junto con los CFC (Fluoro-Cloro-Carbonos) y todos los productos de la agro-industria como el metano: $\mathrm{CH}_{4}$ que producen las bacterias del rumen de los animales que poseen este tipo de estómago compuesto. Estas bacterias que les facilitan su digestión eliminan a la atmósfera este potente gas invernadero $\left(\mathrm{CH}_{4}\right)$. Otra fuente de metano son los extensos cultivos de arroz de todo el mundo en donde las colonias de bacterias (metanógenas/metanótrofas) asociadas a las raíces de este vegetal también desprenden metano a la atmósfera, producto de su metabolismo.

Entre las moléculas del aire que no son gases invernaderos están el oxígeno $\mathrm{O}_{2}$ y el hidrógeno $\mathrm{H}_{2}$ ambos biatómicos.

\section{Tiempo meteorológico y clima de una región}

Mark Twain escribió: "El clima es lo que esperamos, el tiempo es lo que tenemos". Más recientemente Edward Lorenz de la ONU dijo "Tiempo es lo que usted tiene, mientras que clima es lo que usted espera."

En términos prácticos uno se pregunta ¿Cómo está el tiempo? para decidir que ropa usar. Entonces es el tiempo atmosférico o el tiempo meteorológico, la condición de la atmósfera en un lugar y un momento determinado. En relación a la temperatura, la humedad, la cubierta de nubes, etc.

Mientras que al considerar el clima nuestra pregunta es ¿Qué ropa compraré para la próxima temporada? El clima hace referencia a las condiciones atmosféricas promedio (por lo menos, de un periodo de un año) en un lugar determinado de la Tierra. Se caracteriza por la temperatura, humedad, presión atmosférica, precipitación, etc.

Estos promedios otorgan una línea de base para comparar con el clima actual. Nos ayuda a responder preguntas como: ¿Estamos teniendo un verano más caluroso que el promedio?

El clima varía siempre, a lo largo de las estaciones y los años. Los inviernos cambian al otoño y después a la primavera. Algunos veranos son más cálidos que otros. Algunos años llueve más que otros. Esto se denomina variabilidad climática.

Las causas de la variabilidad climática son naturales y entre ellas influyen: los ciclos y tendencias que dependen de la órbita de la Tierra alrededor del Sol, la radiación solar que traspasa la atmósfera, la composición química de nuestra atmósfera, la circulación de los océanos y la interacción del océanoatmósfera, y la actividad de la Biósfera (lugar en la Tierra en donde hay vida).

Entre los años 1980 y 2000 la temperatura Global de la Tierra subió 0,35 ${ }^{\circ}$. En el Observatorio de Mauna Loa la concentración atmosférica de $\mathrm{CO}_{2}$ ha aumentado de 277 ppm en 1750 a 408 ppm en el año 2018. El año 2016 en Mauna Loa, fue la primera vez que se observó una concentración de $\mathrm{CO}_{2}$ $>400$ ppm durante todo el año. Con estas determinaciones, los cientificos piensan que nuestro planeta se está calentando a un ritmo muy rápido. Estos cambios bruscos, son causados principalmente por las emisiones de gases de efecto invernadero a la atmósfera. 


\section{El Niño y La Niña}

Uno de los procesos globales naturales de la cuenca del Pacifico que interviene en la variedad climática es el fenómeno de "El Niño" que se manifiesta de manera que la temperatura de las aguas frías de la superficie del Océano Pacífico oriental aumente durante varios meses. Ello trae como consecuencia sequías e incendios forestales en Australia, Indonesia y en algunas partes de Sudamérica, pero también tormentas de verano más débiles en el sur de Asia, entre otros fenómenos. 'El Niño' también está asociado con fuertes lluvias e inundaciones en Chile Central.

En cambio, el fenómeno de 'La Niña'se caracteriza por temperaturas del océano inusualmente frías en el Océano Pacífico ecuatorial oriental y los efectos en Chile se manifiestan en drásticas sequías.

\section{Gases invernaderos también están privando de oxígeno a nuestros océanos}

Un informe publicado recientemente por la Organización Meteorológica Mundial informó que más del 90\% de la energía atrapada por los gases de efecto invernadero va a los océanos. En el año 2018 se registraron nuevos máximos de la temperatura del océano entre 0 y $700 \mathrm{~m}$ de profundidad y entre los 700 y $2.000 \mathrm{~m}$, superando el récord anterior establecido en el año 2017. En abril de 2019, los biólogos marinos informaron que los peces considerados como los "buzos de aguas profundas" como son el atún y pez espada, que cazan en aguas profundas mayores a los $200 \mathrm{~m}$., hoy en día se les observa aparecer en forma repetida en la superficie para respirar. Este comportamiento ha sido interpretado como resultado del calentamiento del océano que ha disminuido la solubilidad de los gases. La solubilidad de los gases en el agua es inversamente proporcional a la temperatura. Ojalá esto no le ocurra a la corriente fría de Humboldt porque su riqueza en especies marinas se debe a la gran cantidad de oxígeno disuelto lo que le permite tener una enorme productividad biológica útil para la alimentación humana. Si la corriente aumenta su temperatura disminuirá su productividad.

\section{Sequía en Chile Central}

Chile tiene una dependencia directa de la relación océano-atmósfera, por lo cual recibimos la nubosidad proveniente de la evaporación del Pacifico y por ello tenemos presencia o ausencia de precipitaciones cuando las nubes se aproximan a la cordillera de Los Andes. Boisier y cols ${ }^{1}$ del Departamento de Geofisica de la Universidad de Chile, demostraron que en la Zona Centro Sur de Chile -en 287 estaciones ubicadas entre los $30^{\circ}$ y $40^{\circ}$ de latitud sur-las precipitaciones vienen disminuyendo en un periodo de 35 años (1975 a 2014), a una tasa de $65 \mathrm{~mm}$ anuales por década. Esta sí, que es una información robusta de "clima" porque se considera para el cálculo de las condiciones en un periodo de más de 30 años. Pudieron concluir que solo una parte de la disminución de precipitaciones es atribuible a causas naturales (relación océano-atmósfera) frente a Chile. Destacan que la sequía extrema iniciada en el año 2010 se debe atribuir por lo menos en un 25\% a la influencia de origen antropogénico. En ella están los cambios en el uso del suelo (incremento de la actividad agro-industrial), la degradación del ambiente, la urbanización en zonas en donde había una cubierta de vegetación nativa, la disminución de la biodiversidad, el aumento de la población y las migraciones, etc. Todas estas acciones son muy relevantes en la actual sociedad chilena.

\section{El empleo de antimicrobianos en cultivos masivos}

La resistencia a los antimicrobianos (RAM) ha pasado a ser otra forma de Cambio Global porque se presume que estos microrganismos van progresando y mutan a formas cada vez más resistentes a los actuales antibióticos.

Es indispensable abordar en forma integrada por los seres humanos, animales y el medio ambiente este aspecto de las RAM, y para ello se ha diseñado una propuesta de proyecto Latino Americano denominada "Contención de la RAM en los sistemas de producción de alimentos terrestres y acuáticos, bajo un enfoque de salud en América Latina". En Santiago, se realizó recientemente en marzo de 2019, una mesa técnica titulada "Industria de piensos e industria de la carne, su rol en la RAM". Se está trabajando en base a la gran experiencia desarrollada y en 2019 se realizarán más de estas actividades que contemplan los componentes de un sistema de contención de la RAM en los sectores pecuario y acuícola.

Considerando que la globalización de la economía es un factor importante en el tratamiento de 
posibles enfermedades de animales criados para consumo humano, se están impulsando cambios en la mitigación de la amenaza de la RAM basado en el éxito obtenido en este aspecto en Dinamarca y con las acciones de la FAO (Food and Agriculture Organization, Naciones Unidas).

Como podemos apreciar, toda acción humana está repercutiendo de una u otra manera en el sistema Tierra. Debemos estar conscientes de estos hechos o acciones para evitar entregar un sistema menos amable a las próximas generaciones, el sistema Aire, Mar y Tierra constituye un todo único e inter relacionado.

Recientemente Boisier y cols ${ }^{2}$ publicaron un drástico mensaje cientifico a los gobernantes de Chile; señalando que hay evidencias de observaciones de largo tiempo y con la aplicación de modelos de simulación climática que demuestran que la tendencia y los escenarios poseen un sustancial estrés a la sociedad chilena y a sus instituciones, y llaman a una urgente acción tendiente a adoptar medidas de adaptación para mitigar los efectos.

\section{Impacto del cambio global en la salud humana}

Este impacto ha sido enfatizado en un afiche difundido por Asthma \& Respiratory Foundation New Zealand (www.asthmafoundation.org.nz). Con el contenido conceptual de ese anuncio se elaboró la siguiente tabla, que resume y ejemplifica las múltiples formas en que el cambio climático puede afectar a la salud humana.

\section{Impacto del cambio climático en la salud humana*}

\begin{tabular}{|lll|}
\hline Efecto primario & Efectos secundarios & Impactos en salud humana \\
\hline Aumento de temperatura & Calores extremos & Mortalidad; fallas cardiovasculares \\
& $\uparrow$ Severidad climática & Lesiones, $\Delta$ salud mental \\
$\begin{array}{l}\text { Aumento de la concentración } \\
\text { de } \mathrm{CO}_{2}\end{array}$ & $\begin{array}{l}\text { Degradación ambiental } \\
\text { Desabastecimiento de agua y }\end{array}$ & $\begin{array}{l}\text { Migración forzada } \\
\text { Conflictos civiles, } \Delta \text { salud mental }\end{array}$ \\
& $\begin{array}{l}\text { Desnutrición; Enfermedades entéricas } \\
\text { (diarreas) }\end{array}$ \\
$\begin{array}{l}\text { Aumento del nivel de los } \\
\text { océanos }\end{array}$ & $\begin{array}{l}\text { Deficiente calidad del agua } \\
\text { Cambios climáticos extremos: } \\
\text { sequías-inundaciones }\end{array}$ & $\begin{array}{l}\text { Infecciones: cólera, } \\
\text { criptosporidiosis, leptospirosis... }\end{array}$ \\
& $\begin{array}{l}\text { Aumento de alergenos } \\
\text { Florecimiento de algas }\end{array}$ & Alergias respiratorias, Asma \\
& Contaminación aérea & $\begin{array}{l}\text { Malaria, Dengue, Virus Hanta, encefalitis, } \\
\text { Enf. Lyme, Chikunyunga... }\end{array}$ \\
\hline
\end{tabular}

*Fuente: esquema de difusión del Asthma \& Respiratory Foundation, Nueva Zelandia. Símbolos y abreviaturas: $\uparrow=$ aumento; $\Delta=$ cambio; Enf $=$ enfermedad/es.

Entre estos impactos el cambio climático representa una amenaza masiva para la salud respiratoria al promover o agravar directamente las enfermedades respiratorias o al aumentar la exposición a factores de riesgo de estas patologías.

El cambio climático aumenta la cantidad de polen y alergenos producidos por cada planta, la proliferación de mohos y las concentraciones de ozono respirable en el aire y gran cantidad de partículas del suelo.

Para la salud respiratoria humana una menor calidad del aire se traduce en:

- Mayor exposición a alergenos y contaminantes del aire.

- Mayor riesgo de incendios forestales, lo que lleva a la exposición al humo.

- Aumento de la contaminación atmosférica por ozono y / o partículas en el suelo.

En su revisión sobre el impacto climático en la salud respiratoria $D^{\prime}$ Amato y cols ${ }^{3}$ respaldan la labor 
efectuada en Nueva Zelandia, como modelo a seguir. En ese país existen instituciones que monitorean el aire y el agua, con el fin de informar a la población y establecer políticas públicas eficientes. El Cambio Climático es monitoreado por el Instituto Nacional de Investigación de la Corona (NES) y el Instituto Nacional de Investigación del Agua y la Atmósfera (NIWA - National Institute of Water \& Atmospheric Research), estas instituciones formadas en 1992, operan como empresas autónomas.

Se considera que el 'Cambio climático disminuye la calidad del aire que respiramos', por lo tanto, es indispensable que existan centros de control y de prevención de sus efectos sanitarios.

El Gobierno de Nueva Zelandia posee estándares para la calidad del aire que establecen un nivel mínimo garantizado de protección de la salud para todos los neozelandeses, incluyendo: a) Normas de encendido de incendios y productos quemados; b) Normas de aire exterior para: monóxido de carbono, dióxido de nitrógeno, ozono, $P M_{10}$ y dióxido de azufre; c) Estándares para la calefacción del hogar: las estufas a leña en habitaciones urbanas deben cumplir con los estándares de emisiones y eficiencia establecidos por estándares nacionales para la calidad del aire (NES); d) Control de las emisiones de gases de efecto invernadero en los rellenos sanitarios, con el requisito de monitorear las emisiones de gases de efecto invernadero y conocer su aporte a la atmósfera.

Pero aun así a los neozelandeses les quedan desafios por cumplir, algunos de ellos son: a) ¿Cómo lograr que su población esté al tanto de las actividades del NES y del NIWA? b) Conseguir que sus habitantes usen los sistemas desarrollados para mantener informada a la población (ARFNZ): redes sociales, sitio web y boletines para pacientes y profesionales de la salud; c) ¿Cómo cuantificar el empleo de las aplicaciones del NES y monitorear el uso de la red ARFNZ?; d) ¿Cómo lograr vertederos para recopilar datos de emisiones de gases de efecto invernadero; e) Constituir consejos regionales para monitorear la calidad del aire.

En 2018, nuevamente D'Amato y cols ${ }^{4}$ indican que la creciente frecuencia de enfermedades respiratorias obstructivas en los últimos años, en particular el asma alérgica, puede explicarse parcialmente por cambios en el ambiente, con la creciente presencia en la atmósfera de desencadenantes químicos (partículas y componentes gaseosos como el dióxido de nitrógeno y el ozono) y activadores biológicos (aero-alergenos). En personas alérgicas, los aero-alergenos estimulan la sensibilización de las vías respiratorias y pueden inducir síntomas de asma bronquial. Se debe considerar el conjunto de aspectos que afectan el cambio global. Sin embargo, mientras las emisiones globales continúen aumentando, debemos aprender a adaptarnos a la variabilidad del clima. Terminan firmando "La tormenta del asma."

Sabiendo que el Cambio Global posee una presión por la acción del hombre y la sociedad en su conjunto, es indispensable: primero educar al respecto para que desde los niños hasta las generaciones mayores logren tener conciencia de que el problema existe; segundo los tomadores de decisiones deberán ser capaces de establecer políticas públicas en donde la actividad industrial, en especial la agroindustria y la economía en su conjunto conozcan los límites de emisiones de gases invernaderos.

Intentar establecer círculos virtuosos para desarrollar las actividades económicas e industriales ya se afecta la tierra, mar y aire que son un complejo sistema único. El desarrollo de un país debe estar al servicio del hombre, pero también al cuidado del medioambiente.

Si no somos capaces de revertir, los aspectos en que la actividad humana ha intensificado la presión para que se produzca esta mega sequía en Chile, tendremos que pagar muy caro la forma en que se desarrolló la economía, la deforestación, la disminución de la biodiversidad que se cambió por monocultivos, el crecimiento de las ciudades en forma explosiva hacia la montaña, entre otras decisiones. Ojalá aún no sea demasiado tarde para revertir estos impactos. La reunión del COP25 en diciembre, será a lo menos una instancia propicia para hacer presente en qué momento nos encontramos y cómo debemos actuar en el futuro. Por ahora ya sabemos que Nueva Zelandia nos lleva una ventaja de casi 30 años.

Sergio Cabrera Silva

Profesor titular

Programa de Biología Celular y Molecular Instituto de Ciencias Biomédicas

Facultad de Medicina, Universidad de Chile

Email:scabrera@med.uchile.cl 


\section{Bibliografía}

1.- BOISIER JP, RONDANELLI R, GARREAUD R, MUÑOZ F. Anthropogenic and natural contributions to the Southeast Pacific precipitation decline and recent megadrought in central Chile. Geophys. Res Lett 2016; 43: 413-21.

2. BOSIER JP, ALVAREZ-GARRETÓN R, CORDERO RR, DAMIANI A, GALLARDO L, GARREAUD RD, et al. Antropogenic drying in central-southern Chile evidenced by long-term observations and climate model simulations. Elem Sci Anth 2018, 6: 74. Disponible en: https://doi.org/10.1525/elementa.328.

3. D'AMATO G, CECCHI L, D'AMATO M. Climate change and respiratory diseases. Eur Respir Rev 2014; 23: 161-9.

4. D'AMATO M, CECCHI L, ANNESI-MAESANO I, D'AMATO G. News on Climate Change, Air Pollution, and Allergic Triggers of Asthma. J Investig Allergol Clin Immunol 2018; 28: 91-7 doi: 10.18176/jiaci.0228. 